\title{
Potential for high country pasture improvement from planting of rhizome fragments of spreading legumes
}

\author{
D. SCOTT ${ }^{1}$ and C.R. MASON ${ }^{2}$ \\ 'AgResearch, PO Box 60, Lincoln \\ ${ }^{2}$ Landcorp, Christchurch
}

\section{Abstract}

Three legumes, zigzag clover (Trifolium medium), Caucasian clover (T. ambiguum) and crown vetch (Coronilla varia) are notable for their extensive vegetative spread by underground rhizomes but slow initial establishment and low seed set. The possibility of vegetative propagation was considered. A 9-year trial showed the success of transplanting rhizome fragments of different sizes under different fertiliser regimes into hieracium-dominated fescue tussock grasslands. Initial survival and establishment was influenced by fragment size and fertiliser. Subsequent growth was similar for the three species and mainly influenced by fertiliser.

Keywords high country, legumes, pasture improvement, rhizome fragments

\section{Introduction}

Three rhizomatous legumes - zigzag clover (Trifolium mediwn), caucasian clover (T. ambiguum) and crown vetch (Coronifla varia) - have shown potential in high country spaced plant trials (Lobb 1957; Douglas 1970; Daly \& Mason 1987). Zigzag clover along with tall oat grass (Arennatherum elatius) has persisted in some areas from trials dating back to the beginning of the century. Caucasian clover has been showing promise since its introduction in the mid 1960s. Crown vetch has as yet been little tested but appears to suit better the unweathered soils of the low rainfall areas.

All three species share the common features of needing a long establishment period; extensive underground spread by rhizomes; and very low potential seed yields. They characteristically take 4 to 7 years to become apparent in a sward. Their slow establishment and low seed yield imply that seed is always likely to be costly.

However, their desirable characteristic of extensive vegetative spread and high persistence led to the consideration of whether the species could be propagated by transplanting of small rhizome fragments. The trial described investigated that option.

\section{Methods}

The trial was conducted at the trial site at Mt John Station, Lake Tekapo, in hieracium infested fescue tussock on a Tekapo soil on moraine topography of 600 $\mathrm{mm}$ annual rainfall. Rhizome material was collected from old stands of the three legumes and transplanted into the Mt John site in August 1983. The treatment variables were species (3), size of initial fragment (4). fertiliser (3) and replicates (16).

The Caucasian clover material was the cultivar Prairie from a Lincoln University trial on Mespotomia Station. The zigzag clover material was unselected material from the old trial on Hollbrook Station. The crown vetch was a mixture from lines then under test at Haldon Station (Scott 1985).

Rhizome pieces were separated into those with terminal buds and those without. Those with buds were put into three classes: 'small' $(0-50 \mathrm{~mm})$; 'medium' (50$10 \mathrm{~mm})$, and 'large' (100-150 mm). Pieces without buds were cut into $100-\mathrm{mm}$ lengths and termed 'rhizomes'. The larger crown vetch pieces were separated into two classes: 'thin' ( $<0.50 \mathrm{~mm}$ diameter) and 'thick' (5-10 $\mathrm{mm}$ ). All species pieces were sown at $2 \mathrm{~m}$ spacings.

The three fertiliser treatments were $\mathbf{0 , 5 0}$ and $200 \mathrm{~kg} /$ ha sulphur superphosphate applied annually per $\mathbf{m}^{2}$ centred on the transplanted fragment. The fragments probably carried rhizobia from the accompanying soil during transplanting but had further inoculum spread over the trial area in November 1983.

The diameter of plants was measured annually in mid summer along two axes. The plants were grazed once annually during the autumn. Further details of methods is given in Mason (1987). The yield of the central $0.2 \mathrm{~m}^{2}$ in the ninth summer were determined by capacitance probe.

\section{Results}

\section{Establishment phase}

All the treatment variables had a significant effect on the initial survival of rhizome fragments from transplanting until the third summer.

Survival increased as length of initial size class 
Table 1 Plant survival until 3rd summer in relation to initial fragment size and applied fertiliser $(n=48)$.

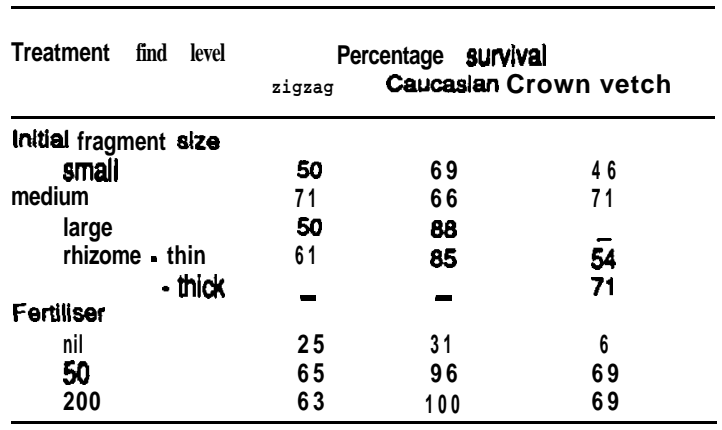

increased (Table 1). For the two clovers the difference between survival of 'small' and 'medium' classes was greater than between 'medium' and 'large'. Survival of rhizome pieces without buds decreased for caucasian clover but increased for zigzag clover. Absence of terminal buds on crown vetch pieces did not affect survival.

Addition of fertiliser at $50 \mathrm{~kg} / \mathrm{ha}$ greatly increased survival with little further increase at a higher rate. The response of zigzag clover to fertiliser was less pronounced than for the other two species.

\section{Subsequent spread}

Fertiliser continued to be the main effect in the subsequent spread of the plants from the third to ninth year (Figure 1). The main contrast continued to be between nil fertiliser and others with little difference between 50 and $200 \mathbf{~ k g / h a}$ super-phosphate.

Crown vetch had the greatest initial spread by the third summer but was surpassed by zigzag clover and caucasian clover in subsequent years. Zigzag clover had double the spread of crown vetch by the ninth year. Zigzag clover and Caucasian clover had similar spread until the fifth year.

The figure gives the mean diameter of all plants within a treatment combination. However there was considerable variation between individual plants. Table 2 shows that although the mean diameter of fertilised zigzag and Caucasian clover plants was about $2 \mathrm{~m}, 10 \%$ of plants exceeded $3 \mathrm{~m}$. Covariance analysis showedthat the increase in size of individual plants was directly correlated with the size of the plant in the third summer. Apart from this, theeffect of initial fragment size did not carry over into subsequent growth.

Each plant colony of zigzag and Caucasian clover had greater size and vigour at the centre resulting in a distinct conical shape to the colony. In attempting to measure the relative yields of treatments in the ninth
Table 2 Size distribution of fertilised zigzag and caucasian clover plants in 3rd and 9th summer.

\begin{tabular}{lccccc}
\hline $\begin{array}{l}\text { Dlameter class (m) } \\
\% \text { plants } .3 r d\end{array}$ & 99 & 1 & $1-2$ & $2-3$ & $>3$ \\
$-9 m$ & 16 & 41 & 33 & 10 \\
\hline
\end{tabular}

summer the measurements were confined to the centre of the colony (Figure 1). These indicate again a major influence of fertiliser with slight difference between the species. These totals include any associated resident species. To estimate the maximum effect these may have had the graphs also show the yields from similar plots in which the treatment species had not established. The growth of the sown legumes gave an advantage over the response of the resident species

Rate of spread diameter In 3rd, 5th, 7th and 9th year
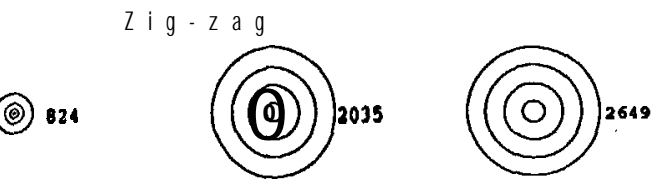

Coucas ion

(2) 738
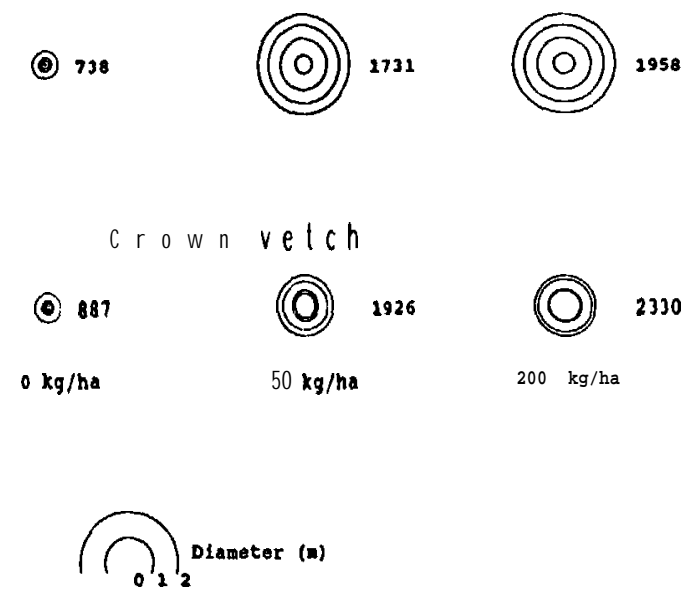

Figure 1 Diameter growth of hizomatous legurnes from 3rd to 9th surnmer in relation to annual fertiliser level. Also standing herbage in 9th summer of anm10.2 $\mathrm{m}^{2}$ of patch.

A feature in many years was that shoots on the expanding edge of a plant tended to be chlorotic suggesting that the rhizome and shoots were growing out faster than the associated rhizobia nodulation. 


\section{Discussion}

'The investigation was undertaken in the context that the ability to use the superior spreading and persistence characteristics of these three legumes could be limited by seed supply and that vegetative propagation might be an option. Establishing plants of zigzag clover, caucasian clover and crown vetch from rhizome segments into hieraciumdominated tussockgrassland has been shown to be possible. The size of rhizome fragments, the presence of absence of terminal buds, and fertiliier affect initial survival. Fertiliser affects subsequent growth.

While the work has demonstrated that the approach is biologically viable it will depend on the development of suitable equipment for the harvesting andresowing of rhizome fragments. This would depend on initial propagation in a loose sandy type soil to both encourage vegetative spread and for ease in removing the bulk of soil material in preparing fragment material. The material might be cut by cross discing, with the results indicating that these should be about $100 \mathrm{~mm}$. The development of a planting device would be difficult though the results indicate plant at every $1-2 \mathrm{~m}$ would be sufficient. Fertiliser would assist both establishment and subsequent growth.

\section{REFERENCES}

Daly, G.T.; Mason. C.R. 1987. Performance of caucasian and zigzag clovers. Proceedings of the NZ Grassland Association 48:151-156.

Douglas, J.A. 1970. The Cockayne plots of Central Otago. Proceedings of the NZ Ecologcal Society 17:18-24

Lobb, W.R. 1957. Zigzag clover may be of value in low rainfall areas. NZ journal of agriculture 94: 183184.

Mason, C.R. 1987. Rhizomatous legumes for hawkweed dominated grasslands. MApplSc thesis, U. of Canterbury.

Scott, D. 1985. Plant introduction trials: genotype environment analysis of plant introductions for the high country. $N Z$ journal of experimental agriculture 13:117-127. 